\title{
RESSIGNIFICAÇÕES CONTEMPORÂNEAS DOS IMAGINÁRIOS RACIALIZADOS NAS ARTES VISUAIS
}

CONTEMPORARY RESIGNIFICATIONS OF RACIALIZED IMAGINARIES

IN THE VISUAL ARTS

\section{Daniel Meirinho}

UFRN

\begin{abstract}
Resumo: Este artigo analisa como contra estratégias de contestação representacional feita por artistas visuais contemporâneos negros podem vir a subverter os estereótipos raciais negativos criados e consolidados nas artes visuais. Desenhos, pinturas e fotografias raciais continuam a compor os imaginários e materiais didáticos, currículos escolares no ensino em artes e história aplicados em todo o país. O processo de ressignificação dos imaginários visuais racializados das imagens coloniais de controle amplificam complexidades da cultura afro-brasileira e redefinem narrativas imagéticas até hoje reiteradas. Este trabalho visa identificar como os modos de transcodificação e resistência em produções visuais contemporâneas reinscrevem significações reducionistas a partir de estratégias estéticas decoloniais negras nas artes enquanto práxis transformadora e de questionamentos raciais.
\end{abstract}

Palavras-Chave: artes visuais, imagens de controle, arte afro-brasileira, visualidades racializadas, artistas negros contemporâneos.

Abstract: TThis article analyses how counterstrategies of representational contestation by contemporary black visual artists can subvert the negative racial stereotypes created and consolidated in the visual arts. Drawings, paintings, and racial photographs continue to make up the imaginary and teaching materials, school curricula in arts and history applied throughout the country. The process of signifying the racialized visual imaginary of colonial control images amplifies complexities of Afro-Brazilian culture and redefines imaginative narratives that have been reiterated until today. This work aims to identify how modes of transcodification and resistance in contemporary visual productions reinscribe reductionist meanings from decolonial black aesthetic strategies in the arts as transformative praxis and racial questioning.

Keywords: visual arts, control images, Afro-Brazilian art, racialized visualities, contemporary Black artists. 


\section{Introdução}

Para ampliarmos uma compreensão em torno do racismo estrutural no contexto brasileiro (ALMEIDA, 2018), seria necessário entendê-lo enquanto um fenômeno conjuntural, que constitui e explica muitas das relações sociais contemporâneas nos quatro cantos do território nacional. Para isso, é importante localizar e abranger alguns fatos que posicionam o país no que acreditamos ser um momento chave das relações raciais no Brasil, que reverbera até hoje em uma espécie de amnésia nacional sobre a escravidão e o apagamento da violência e crueldade imposta ao corpo negro. Este momento simbólico chave se em uma construção narrativa sobre a abolição da escravatura, em seu lento processo de desencadeamento legal que legitimou uma pretensa liberdade à população escrava residente no eixo colonial afro-atlântico. Se por um lado diversas estratégias políticas locais buscaram atenuar a pressão externa internacional, algumas leis serviram como uma estratégia para retardar e dilatar o sistema de cativeiro de forma subtil. A abolição "definitiva" mercantil da escravidão, que só viria em maio de 1888, através de uma lei curta e simples, foi associada a uma ação benevolente da família real imperial vinculada a uma figura coadjuvante à todo o processo, a princesa Isabel (ALONSO, 2015).

A história brasileira por muito tempo tem ignorado a participação e agência dos principais interessados na abolição: os escravos, em suas lutas individuais e coletivas de emancipação através das fugas em massa, insurreições, revoltas e aquilombamentos (NASCIMENTO, 1978). A construção do imaginário coletivo do fim da escravidão e liberdade da população negra escrava sempre foi integrada a atuação e conquistas do movimento abolicionista vinculadas e entendidas como uma questão branca. Aprendemos que foi uma gentileza, um prêmio ou até uma dádiva recebida de liberdade, ofertada aos escravizados, afastando a ideia de uma garantia de direitos impulsionada e protagonizada também pela atuação de personagens negros livres e resultante de ações coletivas de desobediência civil (SCHWARCZ, 2017).

Desde o dia seguinte do ensolarado domingo de 13 de maio, em que Machado de Assis relata as comemorações do fim da escravidão no Brasil após quase quatro séculos, as estruturas políticas brasileiras não conseguiram criar garantias de direitos e de inclusão da população negra, que reverbera até hoje. Sem indenização ou compensação aos recém-libertos, a ausência de uma política de acesso à terra e de integração foi uma das causas da profunda desigualdade racial brasileira contemporânea.

Assim para dizer que a reconstrução do racismo na contemporaneidade se dá na continuidade de uma estrutura política e ideológica criada através de uma pretensa normalidade associada ao binarismo proveniente da estereotipagem racial. A segregação racial faz parte da dinâmica das relações sociais cotidianas brasileiras, através do pretensioso conceito de "democracia racial" que dá direito e poder de definir valores educacionais e morais à apenas um elementos raciais (NASCIMENTO, 1978; ALMEIDA, 2008). Em nenhum outro país das américas a escravidão teve a dimensão brasileira, sendo o último país do ocidente a abolir a escravidão mercantil. A importância do sistema de cativeiro como força de trabalho é resultante da dimensão alargada e impregnada na vida nacional (MACHADO, 2014). Mortari (2015) e Schwarcz (2018) estimam que 45\% de toda a população que deixou a África como escrava desembarcaram no Brasil.

Apenas a longevidade do regime escravista mantido pela corte portuguesa (MAUAD, 2013; VELASQUES, 1985) e pelo Império, já daria conta de explicar o vasto e excessivo acervo icono- 
gráfico sobre a escravidão (SCHWARCZ, 2017). Os valores éticos e morais do regime de trabalho forçado junta-se à justificativa de projeto moderno em um local exótico e tropical, longínquo e isolado, onde se desenvolveria uma "nova civilização” (QUIJANO, 2002). Pela ampla quantidade de pinturas, gravuras, fotografias e ilustrações históricas espalhadas nos museus e acervos etnográficos brasileiros é sabido que a colônia foi visitada por uma infinidade de viajantes, naturalistas, etnógrafos, pintores e ilustradores. Estes produziram uma série de imagens que catalogaram as terras tropicais e os corpos negros nela incorporados, com os mesmos propósitos que estes artistas inventariavam a fauna e flora local.

A construção do racismo contido nas imagens que ilustravam a diáspora afro-atlântica passava pela interpretação de artistas viajantes, na maioria estrangeiros, já que os colonizadores portugueses não contavam com uma tradição de realizar pinturas de paisagem, naturalistas e históricas, dedicando-se, majoritariamente, à arte sacra religiosa (GOMES JR, 2007). Assim, boa parte da larga produção artística iconográfica feita no Brasil durante no período colonial e imperial foi concebida por artistas brancos europeus que incorporaram às suas gravuras, desenhos e fotografias a uma rede de significações socializadas artisticamente e filosoficamente em seus países de origem. O contraste da estrutura binária biológico-determinista da estereotipagem racial determinava o subserviente, indesejável e inaceitável, em oposição ao corpo branco, "parâmetro da autorrepresentação dos indivíduos" (NOGUEIRA, 1998, p. 46).

Essas imagens sempre tiveram exibidas, de forma indiscriminada, nos museus etnográficos e materiais didáticos ilustrando a construção de um imaginário sobre a escravidão e a representação do corpo negro repleto de significações, em uma espécie de relato testemunhal despoli- tizado. Elas construíram e educaram a população brasileira de forma acrítica, com sua capacidade de produzir uma realidade amena e idealizada sem o questionamento das intenções embutidas na lógica visual desta iconografia. Tais estereótipos raciais estéticos foram enraizados com grande esforço nos imaginários coletivos, para fixar estes significados e anular qualquer forma de pluralidade em uma produção visual racializada. Picancio, dos Santos e Boone (2020) argumentam que estas imagens foram e continuam a ser constantemente reforçadas sem contraposições representacionais, educando a população brasileira para "uma única verdade, fazendo com que a totalidade de imagens fosse entendida como a totalidade da realidade" (PICANCIO, DOS SANTOS e BOONE, 2020, p. 102).

Mas então como artistas contemporâneos negros podem modificar esse regime de significação quando inscritos em seus locus de enunciação de lugar epistêmico de subalternidade (BERNARDINO-COSTA e GROSFOGUEL, 2016)? É possível questionar e subverter os paradigmas hegemônicos de representação iconográfica colonialista a partir de narrativas opositoras e estéticas decoloniais (MIGNOLO, 2010)? Este artigo analisa como contraestratégias de contestação representacional feita por três artistas visuais contemporâneos brasileiros podem subverter os estereótipos raciais negativos criados e consolidados nas artes visuais.

Este texto traça um percurso em torno dos processos de representação nas artes visuais coloniais a partir de uma revisão histórica que conecta os imaginários visuais ainda hoje sedimentados por narrativas visuais excludentes de representação da população negra diaspórica. Segue pela importância da problematização em trabalhos e performances artísticos da contemporaneidade através das estratégias de transcodificação, propostas por Stuart Hall, de imagens 
positivas e negativas; inversão de estereótipos; e olhares internos de representação. Estas são aplicadas nas propostas artísticas visuais contemporâneas através de embates e resistências de artistas negros como Rosana Paulino, Yhuri Cruz e Paulo Nazareth, em uma proposta de "tomada de um significado existente e sua colagem em um outro significado" (HALL, 2016, p. 212), como forma de contestação ao regime racializado de representação.

Em contraponto à ausência de amplas visualidades sobre a cultura negra nas artes visuais, enfatizamos na pesquisa como a inclusão de outras imagens podem contribuir no processo de questionamento e educação num país marcado por desigualdades sociais, raciais e culturais. A compreensão do passado colonial nas artes visuais são percebidas a partir da recorrência das "imagens de controle" (COLLINS, 2002), que definiram historicamente os lugares de subalternidade, animalização e inferioridade da população negra. Estes estão a ser deslocados a partir contranarrativas visuais de resistência, enfrentamento e ressignificação dos discursos de controle mantidos com muito esforço pela estrutura de dominação, criada e perpetuada pela matriz colonial de poder (MIGNOLO, 2010).

\section{A escravidão e a estética de representação racista dos negros nas artes visuais}

Paul Gilroy (2007) ao analisar os argumentos colonialistas europeus e da branquitude em torno da escravização negra africana pelo atlântico, aponta que as narrativas suavizavam e justificavam a construção deste imaginário dissimulatório. Grada Kilomba (2019) diz que estas hierarquias raciais moldadas passam pela construção de símbolos fetichisados, objetificados e pitorescos de representação de olhares estrangeiros, externos, em um processo de dessemelhança sobre o outro, onde a branquitude depende da outroridade para se marcar existente (KILOMBA, 2019). Para a autora o conjunto de estímulos exotizados destacam corpos e conceitos pela sociedade branca sobre outros grupos raciais na tentativa de suprimir sua "historicidade de opressão e se construa uma outra enquanto sujeito 'civilizado' e 'decente'” (2019, p. 79).

A consolidação destes imaginários posicionam o sujeito negro na condição de um regime visual de racialização, negativa, em um espetáculo reducionista do outro (HALL, 2016). Quanto mais o colonizador se parecesse com o outro, mais difícil seria comprovar o processo de dominação colonial do indivíduo que necessita recriar e resistir culturalmente e artisticamente marcas de uma identidade cortada de suas raízes (MUNANGA, 2019).

Os traços, estilos, formas e conteúdos podem servistos nas semelhanças reiteradas e repetidas das imagens produzidas em quase todos os países do eixo afro-atlântico, a partir de estruturas visuais normativas e padronizadas do consagrado gênero artístico de viagens pitorescas aos trópicos exóticos. Essas gravuras, desenhos e litografias representaram de forma intencional uma elite agrária colonialista em contraposição com os corpos dos escravos africanos, através de narrativas que dissimulavam a violência do regime, os conflitos e tensões. As imagens de Jean-Babtiste Debret (1768-1844), bem como Frans Post (1612 - 1680), Albert Eckhout (1610-1666), Rugendas (1802-1858) ou ainda Modesto Brocos (18521936) parecem mais elucidar de forma ilustrada a passividade, a omissão e a letargia que o sistema escravocrata prescrevia (LOTIERZO, 2017). As representações de alguma forma acabaram por acalmar e acobertar uma "verdade visual" realista e cruel nos imaginários, "evitando os registros da violência cotidiana praticada durante a escravidão" (SCHWARCZ, 2017, p. 525). 
A construção do racismo contido nas imagens artísticas da diáspora afro-atlântica passa por uma construção científica, pretensamente isenta nos olhares naturalistas, que revelam um conjunto de associações e negações que evidenciam "padrões de intenções" de ordem pictórica (BAXANDALL e PEREIRA, 2006) que serviram como justificativas de domínio e hierarquias. Os estereótipos iconográficos coloniais da negra doméstica leal aos seus senhores, ou empregadores na contemporaneidade, que dedicam sua vida a fornecer cuidado e conforto para os brancos, são conceituados na visão da mãe preta, pensada por Gonzalez (1988) ou figurada pela imagem de controle de subordinação da Mammy, de Collins (2002). As representações modernistas da vendedora de rua, da ama de leite, da mulher negra hipersexualizada, ou do homem negro trabalhador, vigoroso, e até mesmo da criança mestiça bem-vestida, obedecem um padrão visual colonial. Ao mesmo tempo, faz parte de um ideário político representacional de ordem e controle, reforçado por elementos simbólicos figurativos de significação como o pelourinho, o tronco e o uso de chicote, correntes e máscaras.

As fotografias de Marc Ferrez (1843-1903), Augusto Stahl (1828-1877), Albert Henschel (18271882) e Christiano Júnior (1832-1902) eternizaram, através dos cartes-de-visite, um acervo da escravidão, disseminado de forma quase "didática" do lugar que este corpo subalterno e subserviente estava inscrito socialmente. Por vezes constrangidos, ou ostentando suas ferramentas de trabatho e habilidades laborais, os ateliês e estúdios reconstituíam ambientes neutros que encobriam qualquer demonstração de violência que essas imagens indicavam (SCHWARCZ, 2017). O jogo de ver e não olhar se reflete até hoje no anonimato e desconhecimento, ou interesse, de quem eram essas pessoas escravizadas fotografadas.
Reconhecer e identificar esses elementos simbólicos nos possibilita perceber e questionar os estereótipos que atravessam as representações pictóricas e históricas da população negra nas artes visuais brasileiras. Imagens que influenciaram e induziram a construção de um imaginário, anularam a alteridade e singularidade do sujeito negro brasileiro na produção artística e posteriormente midiática (CONDURU, 2007; MUNANGA, 2019; ARAÚJO, 1988; MENEZES NETO, 2018). As gravuras tropicais, pinturas naturalistas, fotografias científicas de tipos nus de frente e perfil enalteceram a colonização e alimentaram convenções visuais pitorescas que reverberam até hoje. O corpo negro sempre esteve disposto esteticamente nas artes visuais representacionais em uma lógica e estrutura política visual reducionista e excessiva (NOGUEIRA, 1998). Os significados foram fixados através de marcas rígidas ora por distinção biológica, ora degeneração (no caso da miscigenação), e até por dessemelhança, como uma estratégia institucionalizada de "embraquecimento sistemático" (NASCIMENTO, 1978, p.69) do povo e da produção de significados no imaginário brasileiro.

É inegável o elo histórico entre uma cadeia de produção de imagens pictóricas coloniais e os imaginários contemporâneos distorcidos e estigmatizados da população negra no país. 0 conjunto de representações visuais objetificadas do corpo negro, fundam a arte renascentista representacional brasileira (ARAÚJO, 1988) e se consolidam nas imagens modernistas, midiáticas e na literatura nacional. O antropólogo brasileiro-congolês Kabengele Munanga, que vem a conceituar o termo arte afro-brasileira, recorda a importância da memória individual e coletiva para a preservação, continuidade e resistência de elementos culturais, especialmente em novos arranjos sociais. Os elementos auto representacionais de artistas negros sempre se vin- 
cularam a um espaço significativo de uma arte utilitária e funcional referente à religiosidade e aos cultos ancestrais (MUNANGA, 2019).

O papel doméstico de servidão inscreve e dissemina o corpo negro nas vanguardas artísticas brasileiras através de uma visão antropofágica modernista. Na tentativa da representação de uma identidade e cultura afro-brasileira, o legado da escravidão enraizava em difusões de imagens a partir de um olhar aristocrático marcado pelo ambiente patriarcal de uma elite branca, progressista e republicana. A "mãe preta" da obra A Negra, de Tarsila do Amaral, representaria as manifestações afro-brasileiras e indígenas, a serem negociadas e ilustradas pelas mãos brancas nostálgicas e afetivas. A associação das mulheres negras à fantasia mitológica da sexualização da "mulata" ou do homem negro ao trabalhador braçal viril são marcas estilísticas e discursivas dos pintores modernistas Di Cavalcanti e Cândido Portinari. Contudo, não passaram de tentativas de dar evidência à situação de vulnerabilidade social da população negra, influenciada pelas vanguardas artísticas europeias (CONDURU, 2007). Muitos traços de subalternidade, alegoria e fetichismo sobre o corpo negro foram deixados nas obras dessa elite artística brasileira branca, a partir de um olhar colonialista interno (QUIJANO, 2002) que possibilitou um alargamento das relações de dominação racial e distinção social no país. Para autores como Picâncio, Dos Santos e Boone (2020) e Conduru (2007), o lugar social do sujeito negro no modernismo não passa de uma transferência do cenário de representação e relocação, influenciado pelos grupos progressistas que tentavam construir uma identidade nacional efetiva. A imagem da mulher livre, na rua, "representada como vendedora, quitandeira, florista, fruteira” (PICÂNCIO, DOS SANTOS e BOONE, 2020, p. 105) pouco difere do olhar de apropriação da escrava trabalhadora do campo e de servidão doméstica. A exploração "da condição associada ao trabalho físico” (CONDURU, 2007, p. 106) do homem negro ou aparentemente positiva da mulata, esconde nas entrelinhas a imagem sexualizada e objetificada que ameniza os fatores raciais para torná-la símbolo artístico a ser exportado pelo modernismo brasileiro.

\section{O novo olhar opositor na construção de ima- ginários contemporâneos: Rupturas e dispu- tas}

É bem possível afirmarmos um processo de silenciamento da contribuição do artista afro-brasileiro negro, como sujeito ativo responsável por uma produção artística nacional, na formação de uma história da arte brasileira (ARAÚJO, 1988). Desde o barroco brasileiro, tão pleno de singularidades afrodescendentes, a presença do artista negro dialoga com demarcações estéticas e construções de subjetividades não-coloniais (MIGNOLO, 2010), percebidas nas associações simbólicas com o universo sincrético religioso, ancestral, cultural e social afrodiaspórico (MUNANGA, 2019).

As produções de uma arte brasileira negra no século XX demarcam a sistematização de experiências de uma corporeidade ancestral, histórica e cultural através do resgate de memórias, de resistências e confrontamentos. Artistas como Rubem Valentim (1922-1991), Heitor dos Prazeres (1898-1966), Mestre Didi (1917-2013), Emanuel Araújo (1940) e Abdias do Nascimento (1914-2011) abandonam o anonimato e a clandestinidade das casas de culto e ampliam o conceito das artes "populares". Nesse contexto, a complexidade e a riqueza temática de artistas contemporâneos como Rosana Paulino (1967), Ayrson Heráclito (1968), Eustáquio Neves (1955), Sonia Gomes (1948), Eneida Sanches (1962), Lídia Lisboa (1970), Sidney Amaral (1973) vêm se 
consolidando no cenário artístico nacional e internacional, com participações em espaços - como bienais e exposições - de legitimação e validação artística.

Trata-se de um processo que, nos últimos anos, adensou-se de modo notável, em que a questão da negritude e decolonialidade deixaram de ser uma proposta temática ou localizada nos espaços urbanos e periféricos e ganharam o cubo branco. Jovens artistas como Jaime Lauriano (1985), Daniel Lima (1973), Renata Felinto (1978), Michelle Mattiuzzi (1983), Paulo Nazareth (1977), Priscila Rezende (1985), Aline Motta (1974), Moisés Patrício (1984), Dalton Paula (1982), entre outros, passaram a ocupar espaços expositivos de museus e galerias reconfigurando novas discussões e perspectivas sobre o racismo contemporâneo. A negritude passa a ser representada de forma imageticamente contestatória, dentro da lógica da representação da estética do realismo "positivo", a qual Stuart Hall (2016) aponta como "estratégia para contestar o regime racializado de representação” (p. 216) das imagens de dominação negativas.

Corpos negros passam a estar presentes nos espaços expositivos, distintos das imagens caricatas e estereotipadas. Em suma, essa geração de artistas contemporâneos funda um movimento estético-político reagente às relações binárias de dessemelhança, poder e de representatividade nas artes visuais brasileiras racializadas. São agentes de uma renovação estética e discursiva de narrativas negras no campo artístico, na tentativa de ressignificar a imagem alegórica projetada na história da arte e reproduzida nos processos educativos que formam e alfabetizam a população brasileira. Assim a arte negra funde o objeto do sujeito artista à obra, não apenas na tentativa de demarcar uma categorização ou contexto de subalternidade, mas de trazer uma concepção de contraposição e contestação de como este sempre foi representado e apropriado.

Desse modo, perguntamos por que não trocar as imagens negativas da população negra, utilizadas para formar o imaginário brasileiro no ensino da arte e da história, por imagens positivas e contestatórias nos materiais didáticos, como uma proposição de inversão de estereótipos? Essa geração de artistas já reconhece um cenário de debate de um regime racializado de representação por várias imagens e estratégias já pontuadas. Como afirma Emanuel Araújo (1988), a contribuição e perspectiva negra nas artes, na educação e na formação de uma cultura brasileira nunca foi interesse artístico ou acadêmico de grande relevância, que movesse uma estrutura de representação. A relevância da produção de arte afro-brasileira diaspórica, até pouco tempo, sempre foi restrita a um plano secundário, limitada a trabalhos isolados e incompletos, criando uma lacuna no estudo nas artes visuais negras enquanto produção cultural e artística inferior na academia.

Essa falta representatividade artística negra se reflete nas salas de aula e materiais didáticos históricos e de educação artística. À omissão e indisponibilidade de referências da arte afro -brasileira se somam a falta de uma perspectiva crítica questionadora da estética colonial de controle e de dominação, reproduzida nas imagens que ilustram os conteúdos educativos e livros didáticos. Os educadores, sem nunca terem tido uma formação relativa a uma estética negra afro-atlântica, ou aos elementos simbólicos africanos, reproduzem ainda "o agravante da ideologia do embranquecimento e do mito da democracia racial imposta pelos setores hegemônicos da sociedade" (DOSSIN, 2008, p. 245). Ou ainda são reduzidas, apenas, a imagens que conotam e promovem símbolos religiosos de cultos afro-brasileiros, em uma justificação de proibidos, em uma "educação laica". O estudo 


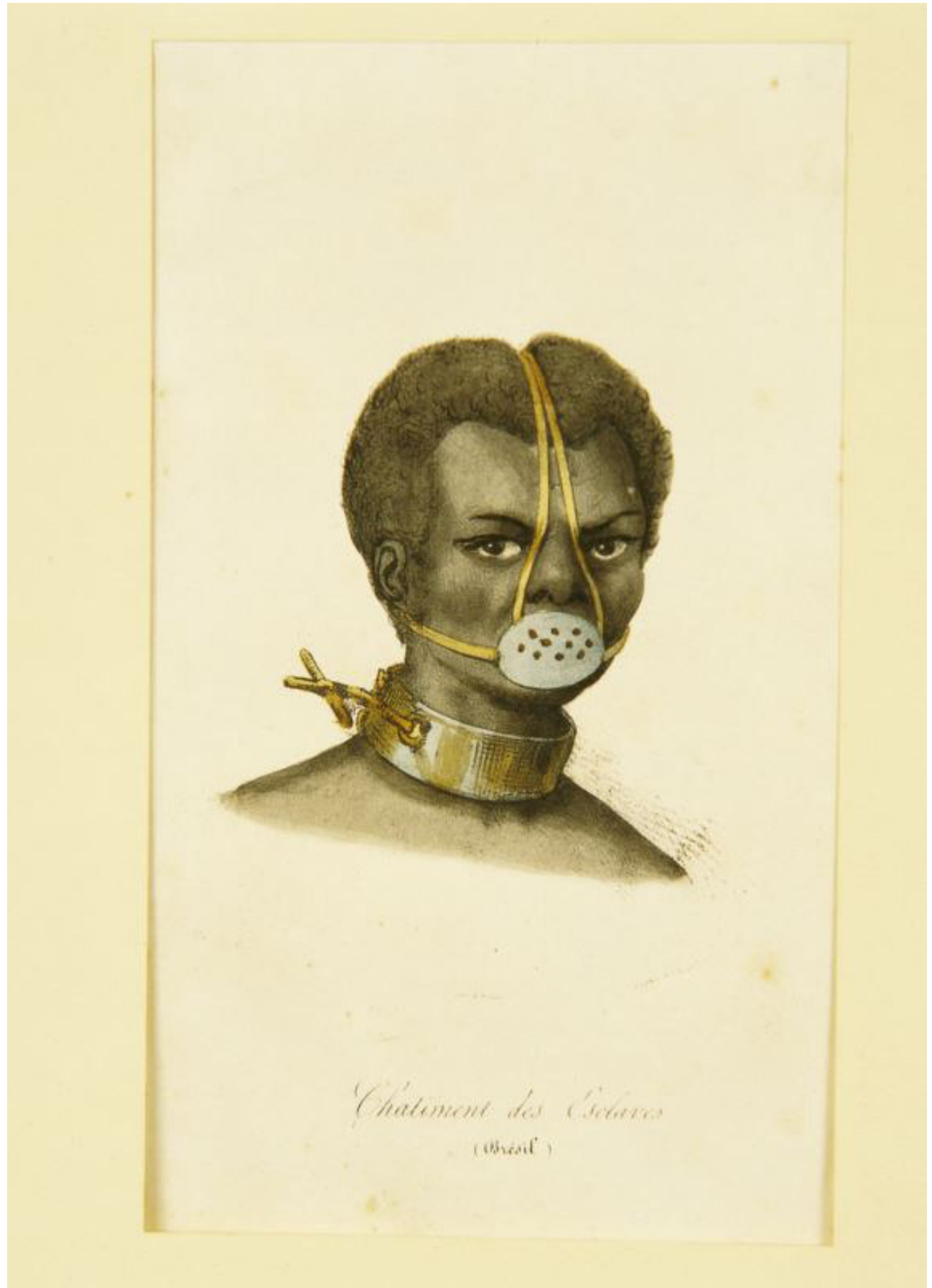

Figura 1. Castigo de Escravos (1839), Jacques Etienne Arago. Litografia aquarelada sobre papel (sem dimensões definidas). Fonte: Coleção Museu AfroBrasil 
da história da arte brasileira tem negligenciado uma análise mais contextual das estratégias estéticas coloniais e fatos históricos, assim como tem descartado a presença do artista negro, valorizando desproporcionalmente uma visão de mundo branca nas artes visuais.

Esta virada de paradigma parece ter tido um impacto positivo com à criação da Lei n. 10.639, de 9 de janeiro de 2003, que tornou obrigatório a inclusão de conteúdos referentes à história e cultura afro-brasileira nos currículos escolares, "em especial nas áreas de educação artística e de literatura e história brasileiras" (BRASIL, 2003). Se a construção de uma identidade nacional se dá pelo reconhecimento e memória, o que esperar de uma sociedade educada a partir de uma ideologia da branquitude superior e de uma cultura e história dada como inferior e subjugada?

Mesmo com a importância da lei, bem como outros incentivos como do Programa Nacional do Livro Didático (2007), muitos educadores encontram barreiras e limitações em cumprir a proposta. Seja por despreparo, desconhecimento da lei ou falta de conhecimentos específicos, grande parte dos professores encontra dificuldades em implementar outras representações visuais que problematizem e questionem as reduções de subjetividade das imagens de controle (COLLINS, 2002), ou das imagens negativas (HALL, 2016) racializadas. Essa ausência dificulta uma práxis transformadora de imaginários e questionamentos críticos raciais.

\section{Estratégias de transcodificações nas artes vi- suais contemporâneas}

Stuart Hall (2016), a partir de uma releitura de Bakhtin e Voloshinov, apresenta a ideia de transcodificação como uma estratégia que visa tomar um significado existente e reapropriarse dele para criar significados (HALL, 2016). As estratégias de transcodificação buscam contestar o regime racializado de representacão a partir de três perspectivas: transformar imagens negativas em imagens positivas; a inversão de estereótipos dentro dos próprios estereótipos; e os olhares internos e lugares de fala na representação.

Nas última década podemos perceber novos olhares opositores sobre as narrativas artísticas contemporâneas. Estes tentam ressignificar o sujeito negro, servindo de referências visuais atualizadas que deslocam padrões estéticos sensoriais das imagens coloniais de controle (COLLINS, 2002). Propomos aqui apontar iniciativas de três artistas que conseguem, por meio de suas obras e performances, construir modos de resistência a perspectivas imagéticas consolidadas sobre as subjetividades negras. Na tentativa de delinear estas ações artísticas de contraponto na arte contemporânea brasileira, são identificados os três modos de estratégias de transcodificação, proposto por Stuart Hall (2016).

\section{A. Corrigindo o equilíbrio: imagens positivas}

A série Bastidores (1997), da artista visual paulista Rosana Paulino, apresenta entre as seis imagens de mulheres negras com seus olhos, testa e garganta costurados, duas de figuras femininas com suas bocas suturadas numa ponte simbólica à máscara de flandres enquanto objeto de tortura e a vontade de silenciamento dos negros. Kilomba (2019) faz uma construção sólida do significado da máscara que servia para evitar que os escravos comessem das plantações, engolissem pepitas de ouro e evitasse que os negros cativos ingerissem terra como forma de apagar suas existências e violências a que estavam submetidos. A litografia Castigo de Escravos (Figura 1), do pintor francês Jacques Etienne Arago retra- 
Figura 2: Bastidores (1997), Rosana Paulino. Fonte: Museu de Arte Moderna de São Paulo - MAM ta uma trajetória de violência sofrida pelo mito da escrava Anastácia ${ }^{1}$ e reverbera a representação da mulher negra na sociedade e na história da arte (SIMIONI, 2010). Esta imagem ilustra até os dias atuais livros de história e nossos imaginários sobre a negritude.

Paulino vem a contestar o silenciamento contido na gravura colonial na terceira e quinta fotografias aplicadas em tecido e suturada (Figura 2), em um vínculo referencial de contraposição existente entre a delicadeza do bordado e a dor, o trauma da violência doméstica da condição negra feminina, impedida de existir senão sob as lógicas da anulação, da subserviência e do controle. A representação interna (HALL, 2016) da artista contemporânea negra incide a partir de uma forma de subversão no corpos de muIheres negras, possibilitando um deslocamento simbólico incômodo, através de significação atualizada de figuras femininas que continuam apagadas e amordaçadas, impedidas de gritar sobre as violências e opressões compulsórias, também vistos nas imagem de controle Mammy (COLLINS, 2002).

Outra estratégia para contestar o regime racializado nas artes passa pela tentativa de substituir imagens "negativas" coloniais por re-

1 A sua existência ainda é colocada como dúvida por alguns estudiosos. Contudo, o mito histórico referencia que Anastácia é filha de Delminda, que chega ao Rio de Janeiro pelo navio negreiro Madalena, e foi estuprada por um homem branco, ficando grávida. Sua imagem é cultuada como santa e heroína nas religiões afro-brasileiras desde 1968 pela Igreja do Rosário e São Benedito dos Homens Pretos, no Rio de Janeiro. A tentativa de beatificação pelos seus devotos celebra no dia 12 de maio a vida da escrava guerreira. presentações positivas, "desafiando assim o reducionismo dos estereótipos anteriores” (HALL, 2016, p. 216). Em diálogo com este enfrentamento de Rosana Paulino, o artista visual Yhuri Cruz desafia os "padrões de intenção" do regime de visibilidade, propondo "mudar os referenciais do que é visível e enunciável” (RANCIÈRE, 2012, p.64) em sua instalação Monumento à voz de Anastácia (2019), com a imagem da Anastácia Livre (Figura 3 e 4). Ao libertar essa mulher negra escravizada, condenada à mordaça em sua permanência representacional, o artista mostra o que não era visível, produzindo rupturas no tecido sensível das percepções raciais. A imagem pode ser lida partir das teorias decoloniais estéticas (MIGNOLO, 2010), questionando e propondo outras narrativas às imagens de controle conhecidas na história da arte visual. As novas significações desta obra passam por questionamentos da situação da mulher negra, refazendo uma iconografia colonial ao tornar a "escrava santa", com seu "sorriso-segredo (CRUZ, 2019), em imagens e vozes a serem ecoadas e veneradas em santinhos disponíveis para serem levados da exposição.

Como uma estratégia clara de transcodificação de inversão de estereótipos (HALL, 2016), a imagem Anastácia Livre tem sido usada desde 2020, e pelos próximos cinco anos, como imagem ilustrativa dos livros de história da rede Eleva de ensino (Figura 5). O módulo sobre sociedade colonial, do material didático utilizado por mais de 220 escolas ao redor do país, trás a imagem na tentativa de produzir novos imaginários visuais a partir do tensionamento de práticas 


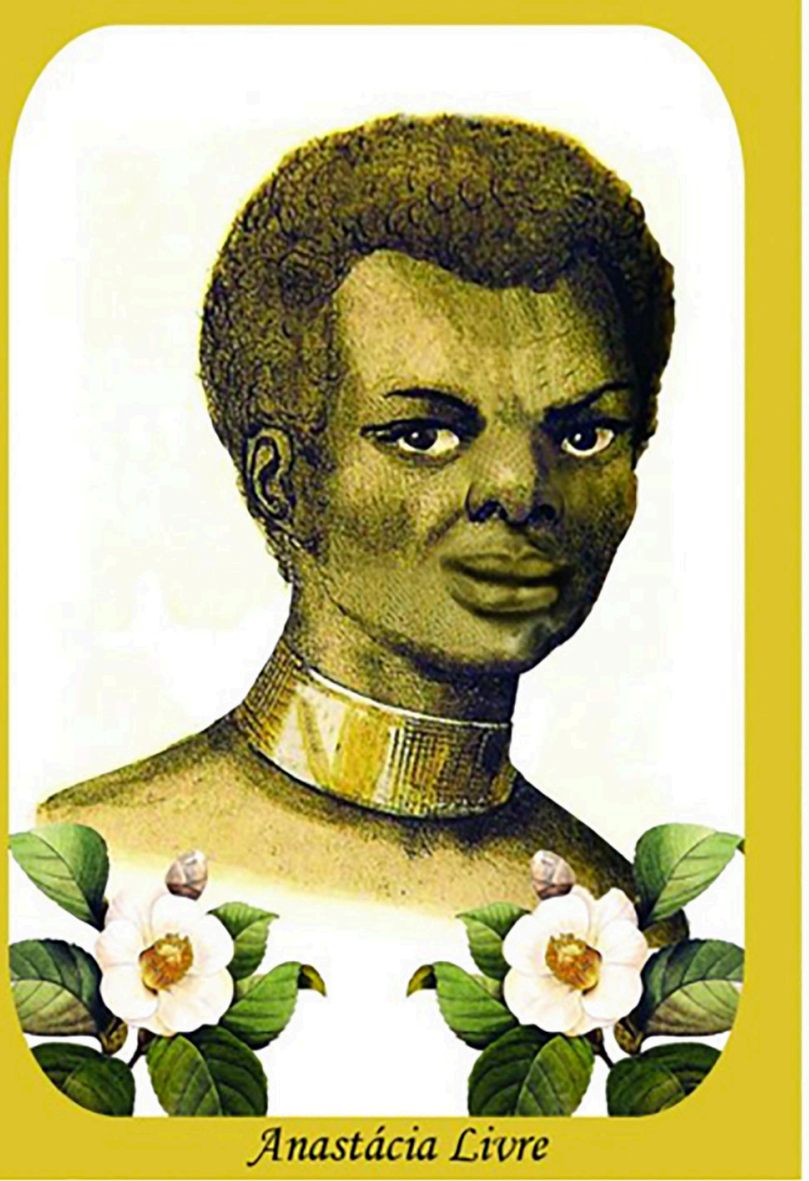

artísticas contemporâneas decoloniais. Estas amplificam a experiência estética e re-significam representações até então racializadas através de imagens negativas. Assim, a imagem da escravidão pode ser fabulada (NYONG’O, 2018) em uma espécie de "fuga do realismo" na criação artística dos povos colonizados e subalternizados, como defende Glissant (2008) em seu conceito de opacidade. Para o autor, ser opaco não se refere a uma obscuridade, mas sim ao potencial criativo e imaginativo que "prefigura o real sem determiná-lo a priori” (2008, p. 54).

Nas produções artísticas de Rosana Paulino e Yhuri Cruz, narrativas de imagens negativas e estereótipos ganham novas significações contemporâneas ao afrontarem as imagens de controle (COLLINS, 2002) e desafiarem um status quo que opera com grande esforço para fixar

\section{Oração a Anastácia Livre}

Festa dias 12 e 13 de Maio.

Comemora-se todos os dias 12 e 13.

Se você está com algum PROBLEMA DE DIFÍCIL SOLUÇÃO e precisa de AJUDA URGENTE, peça esta ajuda a Anastácia Livre.

\section{ORAÇÃO}

Vemos que algum algoz fez da tua vida um martirio, violentou tiranicamente a tua mocidade, vemos também no teu semblante macio, no teu rosto suave, tranquilo, a paz que os sofrimentos não conseguiram perturbar.

Isso quer dizer que sua luta te tornou superior, conquistaste tua voz, tanto que Deus levou-te para as planuras do Céu e deu-te o poder de fazeres curas, graças e milagres mil a quem luta por dignidade.

Anastácia, és livre, pedimos-te ... roga por nós, proteja-nos, envolve-nos no teu manto de graças e com teu olhar bondoso, firme e penetrante, afasta de nós os males e os maldizentes do mundo.

Monumento à voz de Anastácia Yhuri Cruz, 2019

e dar continuidade ao sistema de significação e representação colonial, sedimentado em uma égide de dominação em suas expressões iconográficas racistas e fetichizadas.

Figura 3 - Monumento à voz de Anastácia (2019), Yhuri Cruz. Fonte: Yhuri Cruz (site do artista).

\section{B. Estratégias internas de representação}

Quando Stuar Hall (2016) cria esta estratégia de contestação do regime racializado de representação, ele compreende o caráter instável e mutável do significado, embora reconheça a dificuldade de fixar novos significados dentro da complexidade do poder representacional da branquitude hegemônica. Assim, o autor entende a necessidade de inverter a leitura do fetichismo racial, não como repetição das fantasias racistas, mas como estratégia de desconstrução que revela e desnuda relações sociais e psíquicas do binarismo racial nas representações visuais artísticas. 


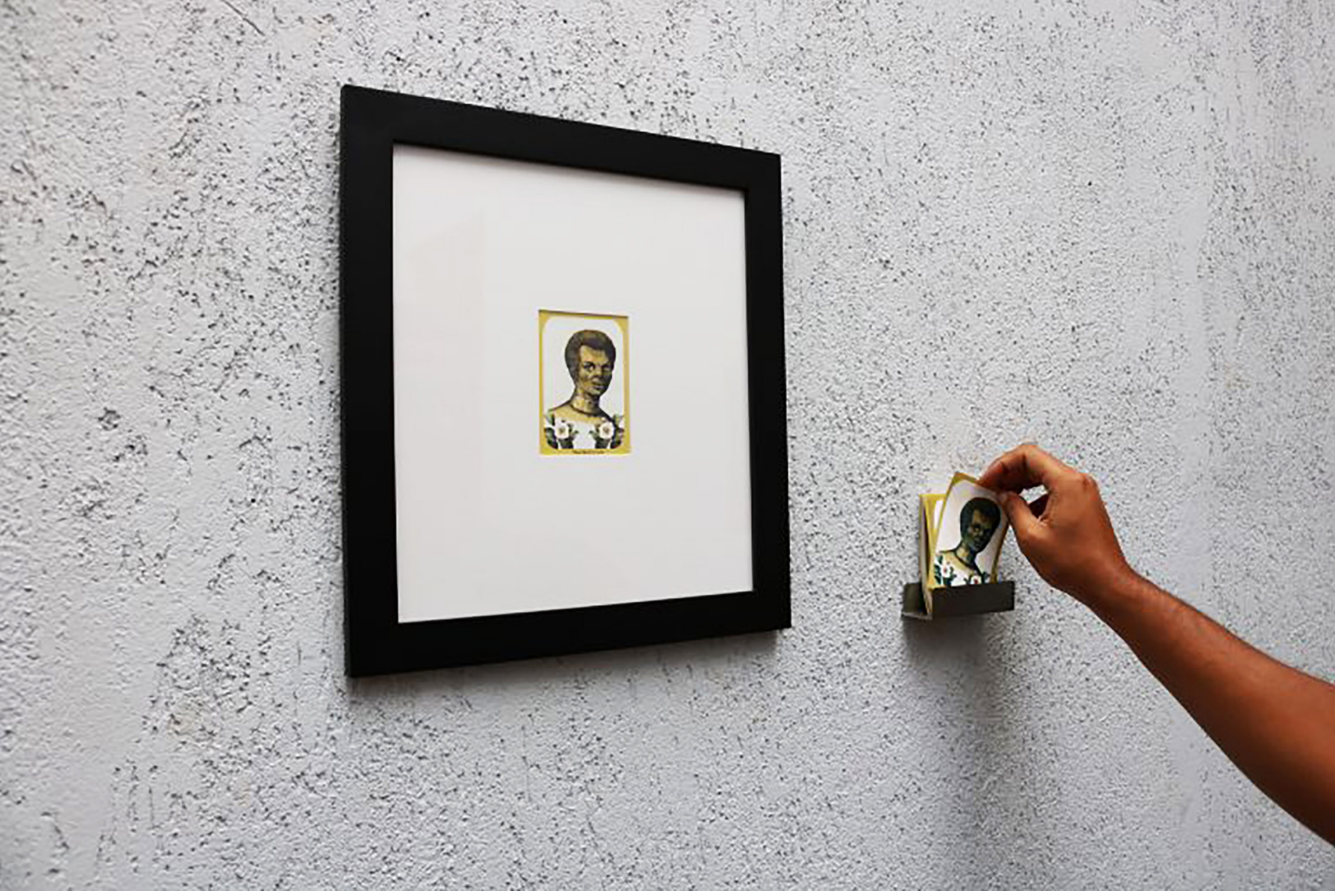

Figura 4 - Monumen to à voz de Anastácia (2019), Yhuri Cruz. Fonte: Yhuri Cruz (site do artista)
A série Para Venda (2011) (Figura 6), do artista mineiro Paulo Nazareth é um exemplo de confronto direto a esse fetichismo racial, provocando deslocamentos implicados na arte contemporânea negra decolonial ao contrastar a obra Escravo com máscara de flandres, de Jean -Baptiste Debret (1835) (Figura 7). A ação performática provoca uma experiência espaço-temporal, passado-presente, através de uma inscrição autobiográfica que descoloniza o olhar sobre o corpo negro a partir do lugar seu de fala. Assim, a fotografia tenta redefinir narrativas imagéticas fetichizadas na busca de ressignificar os sujeitos idealizados como a personificação dos ideais estéticos normatizados (MIGNOLO, 2010). O artista desestabiliza e inverte de forma crítica a imagem fixada no imaginário coletivo pelo olhar branco estereotipado sobre o corpo negro. Uma associação direta ao não humano, em uma estratégia de ambivalência despertada que joga com o conceito de controle, estranheza e posse mercantil do corpo negro.

\section{Conclusões}

Desmontar um regime racializado de representação é um exercício extremamente difícil que não possui garantias absolutas de mudanças de estereótipos e imaginários. Contudo, se faz necessário e urgente a utilização de outras referências e o aprofundamento de perspectivas críticas sobre as imagens artísticas coloniais. A desconstrução de mitos e estereótipos com a inclusão de novas significações e potências 


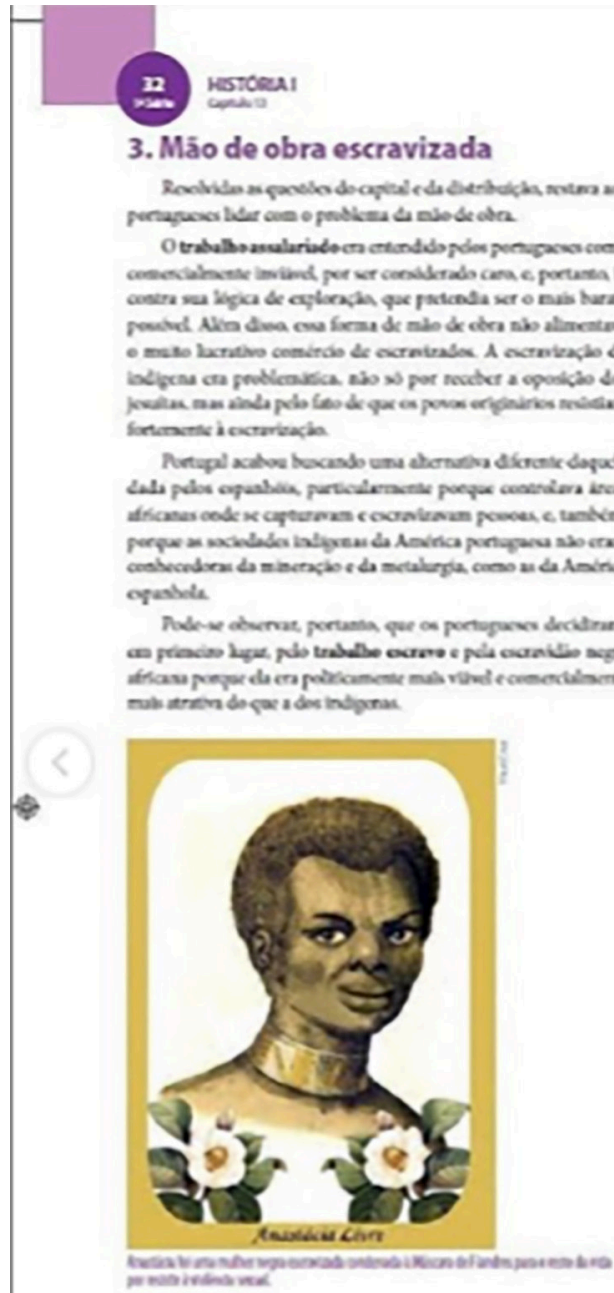

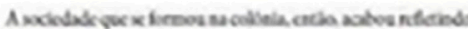

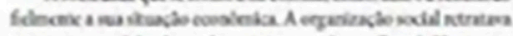

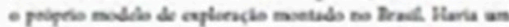

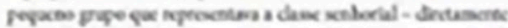

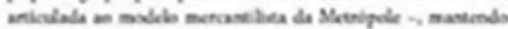

narrativas e discursivas das representações artísticas contemporâneas negras deslocam os olhares e as perspectivas. Mais do que idealizações envoltas em estereótipos, as imagens de controle servem à estrutura de poder da colonialidade (QUIJANO, 2002), uma vez que fazem perdurar pressupostos subalternizantes a respeito do corpo negro.

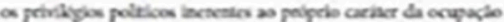

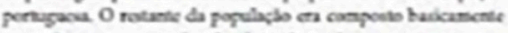

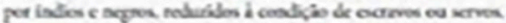

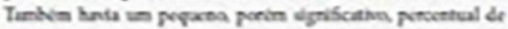
bemeas Lino andriabs

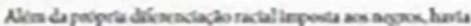

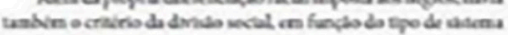
cocolation moctable ne Bral.

\section{Sociedade colonial}

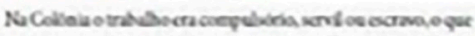

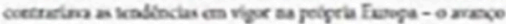

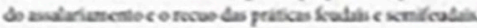

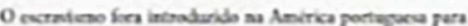

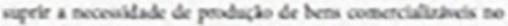

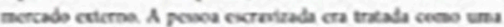

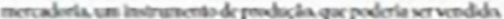

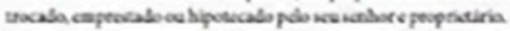

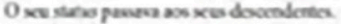

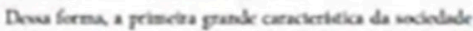

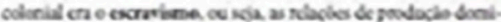

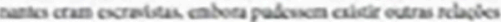

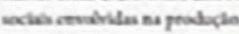

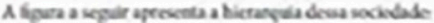

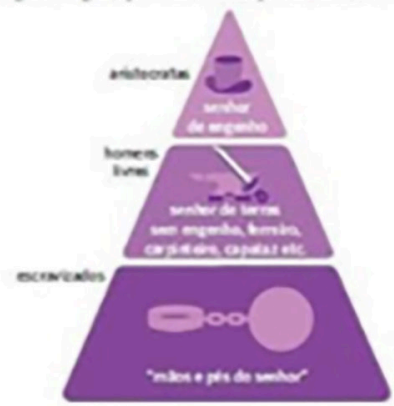

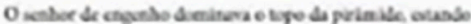

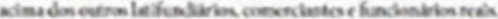

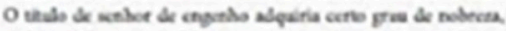

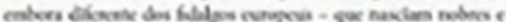

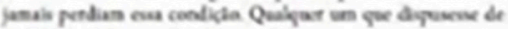

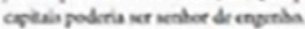

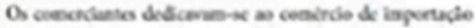

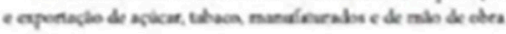

Enquanto as imagens de controle servem aos variados sistemas de opressão que atravessam os corpos subalternizados da "matriz de dominação" (COLLINS, 2002), as estratégias de ressignificação dos imaginários visuais podem ampliar a compreensão das complexidades da cultura afro-brasileira, reiterando suas ancestralidades, memórias
Figura 5 - Edição de 2020 do material didático de História I da rede Eleva de ensino. Fonte: Instagram do artista (Yhuri Cruz) 


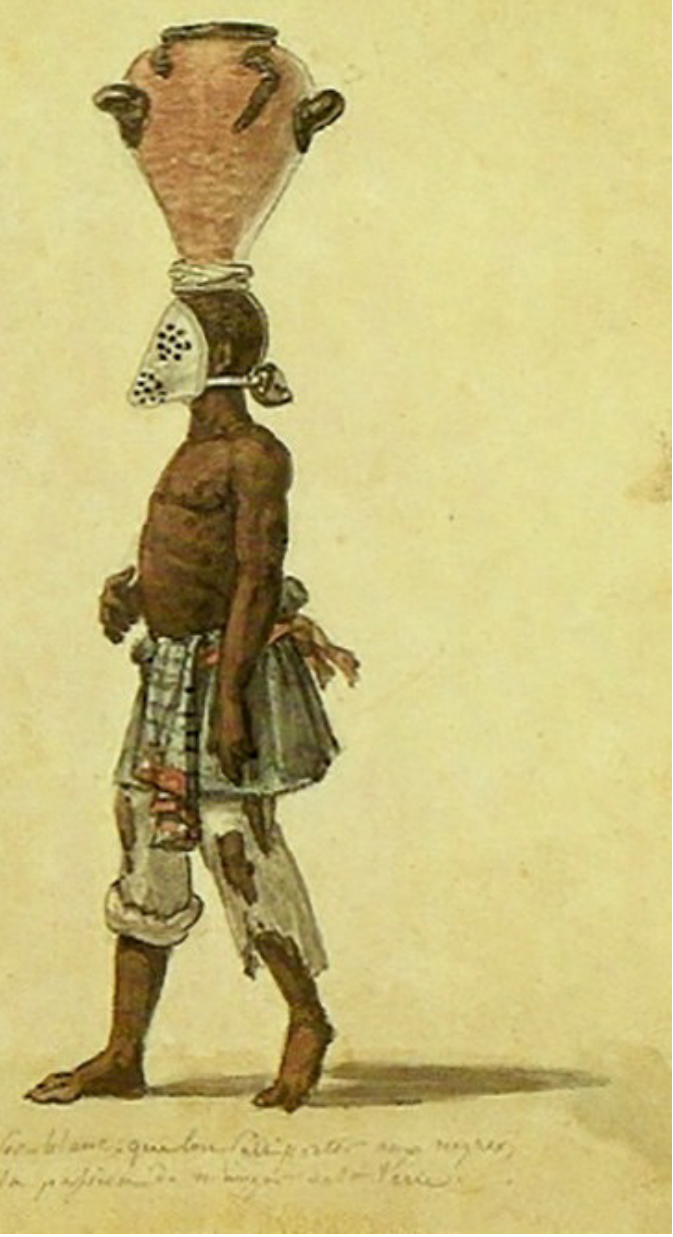

Figura 6 - Escravo com máscara de flandres. Jean-Baptiste Debret (1835). Litografia aquarelada sobre papel. Fonte: Coleção Museu AfroBrasil.

Figura 7 - Sem título, da série Para Venda (2011), Paulo Nazareth. Fotografia a cores. Fonte: divulgação e lutas, redefinindo narrativas imagéticas até hoje reiteradas.

Novas imagens devem compor os processos educativos e materiais didáticos nos currículos escolares com o intuito de expandir e repensar as imagens de subjugação da população negra a partir de novas configurações estéticas e políticas da contemporaneidade. Rosana Paulino, Yhuri Cuz e Paulo Nazareth são apenas alguns dos exemplos de artistas visuais contemporâneos negros que criam estas significações e contestações a partir de embates discursivos, narrativos e estéticos, viabilizando a arte negra como uma nova iconografia que pode ser

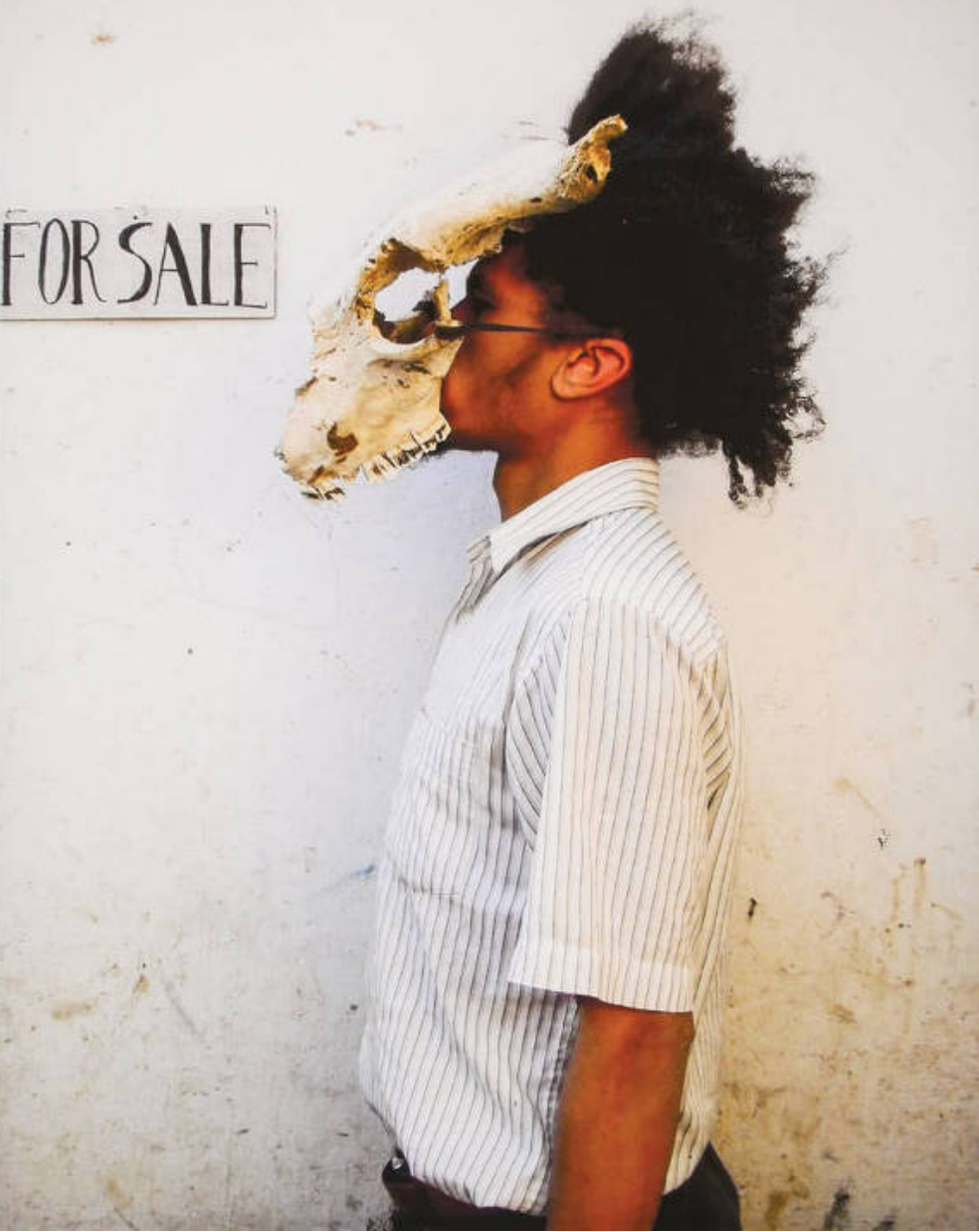

sedimentada no imaginário brasileiro. Suas contranarrativas visuais podem possivelmente apresentar soluções referenciais de deslocamentos sensoriais e estéticos que possibilitem redefinir os contextos de controle, em uma tentativa de ecoar as tensões raciais presentes no país em uma reinvindicação política de representatividade.

Os conceitos de imagens de controle e transcodificação, aqui pensado como aparato teórico-metodológico, servem à compreensão dos pontos de partida destas manifestações. Estabelecem novas imagens que desafiam modos de representação e imaginários cristalizados sobre o corpo 
negro (NOGUEIRA, 1998). Nesse sentido, este trabalho entende que novas práticas artísticas de significação simbólica podem subverter e possibilitar a transcodificação de novos significados para as imagens negativas. O campo da representação não é estático e está ávido por novos padrões emergentes.

\section{Referências}

ALMEIDA, Silvio. Racismo estrutural. São Paulo: Pólen Produção Editorial, 2019.

ALONSO, Angela. Flores, votos e balas: o movimento abolicionista brasileiro (1868-1888). São Paulo: Companhia das Letras, 2015, 529 p.

ARAÚJO, Emanoel (Org.). A mão afro-brasileira: significado da contribuição artística e histórica. São Paulo: Tenenge, 1988.

BAXANDALL, Michael; PEREIRA, Vera Maria. Padrões de intenção: a explicação histórica dos quadros. São Paulo: Companhia das Letras, 2006.

BERNARDINO-COSTA, Joaze; GROSFOGUEL, Ramón. Decolonialidade e perspectiva negra. Sociedade e Estado, v. 31, n. 1, p. 15-24, 2016.

BRASIL. Lei 10.639, de 9 de janeiro de 2003. Altera a Lei 9.394, de 20 de dezembro de 1996, que estabelece as diretrizes e bases da educação nacional, para incluir no currículo oficial da Rede de Ensino a obrigatoriedade da temática "História e Cultura Afro-Brasileira”, e dá outras providências.

COLLINS, Patricia Hill. Black feminist thought: Knowledge, consciousness, and the politics of empowerment. Nova York: Routledge, 2002.

CONDURU, Roberto. Arte Afro-Brasileira. São Paulo: C/Arte, 2007.

$\mathrm{CRUZ}$, Yhuri. Monumento à voz de Anastácia. Disponívelemhttps://yhuricruz.com/2019/06/04/ monumento-a-voz-de-anastacia-2019, acesso em 10 de outubro de 2020.

DOSSIN, F. R. Apontamentos acerca da pre- sença do artista afro-descendente na história da arte brasileira. In: XVII Encontro da Associação Nacional de Pesquisadores em Artes Plásticas, 2008, Florianópolis. Anais do 17o Encontro Nacional da ANPAP. Florianópolis: ANPAP, 2008.

GILROY, Paul. Entre campos: nações, culturas e o fascínio da raça. São Paulo: Annablume, 2007.

GLISSANT, Édouard. Pela opacidade. Revista Criação \& Crítica, n. 1, p. 53-55, 2008.

GOMES JR., Guilherme Simões. Vidas de artistas: Portugal e Brasil. Revista Brasileia de Ciências Sociais, v. 22, n. 64, p. 33-47, 2007.

GONZALEZ, Lélia. Por um feminismo afrolatinoamericano. Revista Isis Internacional, Santiago, v. 9, p. 133-141, 1988.

HALL, Stuart. Cultura e representação. Rio de Janeiro: PUC-Rio - Apicuri, 2016.

KILOMBA, Grada. Memórias da plantação: episódios de racismo cotidiano. Rio de Janeiro: Editora Cobogó, 2019.

LOTIERZO, Tatiana. Contornos do (in)visível Racismo e Estética na pintura brasileira (18501940). São Paulo: Edusp, 2017.

MACHADO, Maria Helena P T. Crime e escravidão: trabalho, luta e resistência nas lavouras paulistas (1830-1888). 2a edição. São Paulo: EDUSP, 2014.

MAUAD, Ana Maria. Fotografia pública e cultura visual, em perspectiva histórica. Revista Brasileira de História da Mídia, v. 2, n. 2, p. 11-20, 2013. MENEZES NETO, Hélio. Entre o visível e o oculto: a construção do conceito de arte afro-brasileira, Dissertação (Mestrado em Antropologia), Universidade de São Paulo (USP), São Paulo, 2018.

MIGNOLO, Walter D. Aiesthesis decolonial. CALLE 14: revista de investigación en el campo del arte, v. 4, n. 4, p. 10-25, 2010.

MORTARI, Claudia. Introdução aos estudos africanos e da diáspora. Florianópolis: DIOESC: UDESC, 2015.

MUNANGA, Kabengele. Arte afro-brasileira: o 
que é afinal?. Paralaxe, v. 6, n. 1, p. 5-23, 2019.

NOGUEIRA, Isildinha Baptista. Significações

do corpo negro. Tese (Doutorado em Psicologia), Universidade de São Paulo, São Paulo, 1998.

NYONG'O, Tavia. Afro-Fabulations: The Queer Drama of Black Life. Nova York UP, 2018.

PICANCIO, Gabriela Valer; DOS SANTOS, Rafael José; BOONE, Silvana. Do animal imoral à total invisibilidade: a representação da mulher negra nas artes visuais e na literatura brasileiras. In: Conexão-Comunicação e Cultura, v. 18, n. 35, 2020.

QUIJANO, Aníbal. Colonialidade, poder, globalização e democracia. Novos rumos, v. 37, n. 17, p. 4-28, 2002.

RANCIĖRE, Jacques. 0 espectador emancipado. São Paulo: Martins Fontes, 2012.

SCHWARCZ, Lilia Moritz; DOS SANTOS GOMES, Flávio (Ed.). Dicionário da escravidão e liberdade: 50 textos críticos. Editora Companhia das Letras, 2018a.

SCHWARCZ, Lilia Moritz. Imagens da Escravidão: o outro do outro (Séculos 16 ao 19) In: Histórias Afro-Atlânticas [vol. 2] Antologia, Org. Adriano Pedrosa, Amanda Carneiro, André Mesquita. São Paulo: Masp, pp. 524 - 538, 2017.

SIMIONI, Ana Paula. Bordado e transgressão: questões de gênero na arte de Rosana Paulino e Rosana Palazyan. PROA Revista de Antropologia e Arte, n. 2, p. 1-20, 2010.

VASQUEZ, Pedro. D. Pedro Il e a fotografia no Brasil. Rio de Janeiro: Fundação Roberto Marinho, 1985.

\section{Daniel Meirinho}

Professor do Departamento de Comunicação Social da Universidade Federal do Rio Grande do Norte (UFRN) e do Programa de Pós-graduação em Estudos da Mídia (PPgEM/UFRN). Doutor em Ciências da Comunicação pela Universidade Nova de Lisboa (UNL, Portugal). Mestre em Comunicação e Artes pela mesma universidade (UNL, Portugal). Pós-doutorado pela Universidade Estadual do Rio de Janeiro (UERJ). Fotógrafo e pesquisador das áreas de fotografia e artes visuais, com ênfase em decolonialidade, identidade racial, representação e resistência na produção de artistas contemporâneos negros. Coordena o projeto "Olhos Negros: Visibilidades e alteridades na fotografia negra contemporânea brasileira" (UFRN) para o mapeamento, catalogação e difusão de fotógrafos negros que atuam em âmbito nacional. 